\title{
Perancangan Sistem Pendukung Keputusan Penentuan Jurusan Siswa Sma Negeri 2 Kutacane Berbasis Web Dengan Menggunakan Metode Analytical Hierarchy Process (AHP)
}

\section{Article Info \\ Article history:}

Received 27 Augustus, 2021

Revised 29 September, 2021

Accepted 01 October, 2021

Keywords:

Decision Support System, Web, Database, Analytical Hierarchy Process (AHP)

\begin{abstract}
The world of education is currently also growing rapidly, with many schools that offer various majors, each of which has its advantages, so that people are also free to choose according to their interests. This makes schools must also have a good system to be able to direct the community to choices according to their abilities. A decision support system (Desicion Support System) can help provide various alternatives that can be taken in the decision-making process. There are many methods that can be used by decision makers to help find the optimal solution or alternative for a problem. The Decision Support System for Determining Majors serves to help schools make the right decisions using the Analytical Hierarchy Process method. The main function of this software is to process data on the selection of high school students majors. This software is implemented using the web, and for the database using Mysql.

This is an open access article under the CC BY-SA license.
\end{abstract}

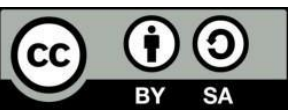

Corresponding Author:

Ariani Susanti

STMIK Budi Darma, Manajemen Informatika, Medan, Indonesia

Email Address: ariani@gmail.com

(C) 2021 The Author: Published by. Cattleya Darmaya Fortuna

\section{Pendahuluan}

Sekolah Menengah Atas adalah jenjang pendidikan menengah pada pendidikan formal di Indonesia [1]. Jurusan di Sekolah Menengah Atas (SMA) digunakan sebagai acuan untuk menyalurkan bakat dan kemampuan dari siswa [2]. Penjurusan pada siswa SMA dilakukan ketika siswa berada dikelas X [3]. Penjurusan siswa merupakan hal rutin yang dilakukan pada Sekolah Menengah Atas (SMA) [4]. Penjurusan belajar siswa SMA merupakan pengelompokan minat belajar untuk mempermudah siswa dalam menekuni bidang ilmu dalam pendidikan tingkat lanjut [5]. Penjurusan dilakukan dengan tujuan untuk mengarahkan siswa agar nantinya dapat menekuni bidang tertentu pada level pendidikan selanjutnya [6]. Penentuan jurusan siswa pada tingkat pendidikan sekolah menengah atas pada umumnya menggunakan rekomendasi hasil psikotes, nilai akademik, minat dan bakat siswa. Tidak semua sekolah memiliki data yang lengkap untuk melakukan penjursan siswa [7]. Sistem yang berjalan pada saat ini masih menggunakan Microsoft excel, sehingga membutuhkan 


\section{Ariani Susanti}

doi.org/10.54209/jatilima. V3i2.152

waktu tidak sedikit. Selain itu memerlukan tingkat ketelitian yang tinggi, sehingga resiko kesalahan dalam proses perhitungan semakin besar. Resiko Kesalahan dalam proses perhitungan penjurusan siswa berdampak pada hasil pemilihan program studi. Oleh karena itu diperlukan sebuah metode baru yaitu Sistem Pengambilan Keputusan untuk proses penjurusan siswa [8] dengan menerapkan metode Analitical hierarcy process (AHP). Sistem pendukung keputusan merupakan suatu sistem yang mampu memecahkan masalah secara efesian, efektif, yang bertujuan untuk membantu pengambilan keputusan dengan memilih berbagai alternatif keputusan [9]. Sistem pendukung keputusan memberikan suatu keputusan yang bersifat semiterstruktur, dimana tidak seorangpun tahu secara pasti bagaimana keputusan seharusnya dibuat [10]. SPK bertujuan untuk menyediakan informasi, membimbing, memberikan prediksi serta mengarahkan kepada pengguna informasi agar dapat melakukan pengambilan keputusan dengan lebih baik [11]. Sistem pendukung keputusan tidak dimaksudkan untuk menggantikan peran pengambil keputusan, tapi untuk membantu dan mendukung pengambil keputusan [12]. Berdasarkan pengujian yang dilakukan, sistem yang dibuat mampu memberikan hasil yang baik sesuai dengan perhitungan yang digunakan, membantu mempercepat dalam mengambil keputusan [13]. Sistem pendukung keputusan ini dibangun melalui 6 tahapan. Tahap pertama adalah pengumpulan data dan informasi melalui wawancara dan analisis dokumen. Tahap kedua adalah pengolahan data dan informasi untuk mendapatkan rancangan sistem yang akan dibangun. Tahap ketiga adalah analisis sistem yang meliputi input data sekolah, pembobotan kriteria dengan [14] metode Analitical hierarcy process (AHP) harus mengikuti langkah pengerjaan AHP dengan melakukan perbandingan nilai setiap kriteria untuk mengahasilkan matriks perbandingan kriteria, Matriks Bobot Prioritas Kriteria, Matriks Konsistensi Kriteria selanjutnya menetapkan nilai skala perbandingan lokasi berdasarkan masing-masing kriteria. Setelah menemukan bobot dari masing-masing kriteria terhadap alternatif yang sudah ditentukan, langkah selanjutnya adalah mengalikan bobot dari masing-masing kriteria dengan bobot dari masing-masing alternatif, kemudian hasil perkalian tersebut dijumlahkan perbaris. Sehingga didapatkan total prioritas global [15]. Metode AHP yaitu suatu metode yang input utamanya adalah persepsi manusia [16]. Analitical hierarcy process (AHP) adalah suatu teori umum tentang pengukuran yang digunakan untuk untuk sekala rasio, baik dari perbandingan berpasangan yang diskrit maupun kontinu. Analitical hierarcy process (AHP) dapat menyederhanakan masalah yang kompleks dan tidak terstuktur, strategik dan dinamik menjadi bagiannya, serta menjadikan variabel dalam suatu hieraki (tingkatan) metode Analitical hierarcy process (AHP) mempunyai kemampuan untuk memecahkan masalah yang multiobyetif yang berdasarkan pada perbandingan preferensi dari setiap elemen dan hieracki [17].

\section{Metode}

Untuk penentuan jurusan siswa SMA Negeri 2 Kutacane tersebut dibutuhkan kriteriakriteria dari setiap alternatif. Adapun kriteria untuk penentuan jurusan siswa sudah ditentukan oleh pihak sekolah sebagai berikut: Nilai raport, Ranking, Bakat dan Minat Siswa. Penjelasan dari masing-masing Kriteria sebagai berikut:

1. Nilai raport meliputi Nilai: Matematika, Fisika, Biologi, Kimia, Bahasa Indonesia, Bahasa Inggris, Ekonomi, Geografi, Sosiologi dan Sejarah.

2. Ranking adalah urutan kedudukan peserta didik ditengah-tengah kelompoknya

3. Bakat adalah sebagai kemampuan individu untuk melakukan tugas tertentu tanpa banyak bergantung pada upaya pendidikan dan pelatihan.

4. Minat siswa merupakan kriteria pendukung.

Penilaian setiap siswa terhadap kriteria-kriteria yang ada dilakukan dengan model 


\section{Ariani Susanti}

doi.org/10.54209/jatilima. V3i2.152

penilaian yang bersifat kuantitatif. Salah satu metode perhitungan kuantitatif tersebut adalah metode Analytical Hierarchy Process (AHP). Adapun langkah-langkah metode AHP adalah:

1. Menentukan jenis-jenis kriteria penentuan jurusan siswa.

2. Menyusun kriteria-kriteria tersebut dalam bentuk matriks berpasangan.

3. Menjumlahkan nilai-nilai dari setiap kolom pada matriks.

4. Membagi setiap nilai dari kolom yang bersangkutan dengan jumlah matriks kolom untuk memperoleh normalisasi matriks.

5. Menghitung nilai prioritas kriteria dengan rumus menjumlah matriks baris hasil langkah 4 dan hasilnya langkah 5 dibagi dengan jumlah kriteria.

6. Menentukan alternatif-alternatif yang akan menjadi pilihan.

7. Menyusun alternatif-alternatif yang telah ditentukan dalam bentuk matriks berpasangan untuk masing-masing kriteria. Sehingga akan ada sebanyak n buah matriks berpasangan antar alternatif.

8. Masing-masing matriks berpasangan antar alternatif sebanyak $\mathrm{n}$ buah matriks, masingmasing matriksnya dijumlah perkolomnya.

9. Menghitung nilai prioritas alternatif masing-masing matriks berpasangan antar alternatif dengan rumus seperti langkah 4 dan 5 .

10. Menguji konsistensi setiap matriks berpasangan antar alternatif dengan rumus masingmasing elemen matriks berpasangan pada langkah 2 dikalukan dengan nilai prioritas kriteria. Hasilnya masing-masing baris dijumlah, kemudian hasilnya dengan masingmasing nilai prioritas kriteria sebanyak $\lambda 1, \lambda 2, \lambda 3 \ldots . . \lambda \mathrm{n}$. Menghitung nilai lamda maksimum dengan rumus:

$$
\lambda \text { maks }=\frac{\sum \lambda}{n}
$$

11. Menghitung Consistensi Index (CI) dengan rumus :

$\mathrm{CI}=(\lambda$ maks-n $) / \mathrm{n}-1$

Dimana $\mathrm{n}=$ banyaknya elemen

12. Menghitung Rasio konsistensi, dengan rumus:

$C R=\frac{C I}{R I}$

Tabel 1. Random Consistency

\begin{tabular}{|l|l|l|l|l|l|l|l|l|l|l|}
\hline $\mathbf{n}$ & 1 & 2 & 3 & 4 & 5 & 6 & 7 & 8 & 9 & 10 \\
\hline RI & 0.00 & 0.00 & 0.58 & 0.90 & 1.12 & 1.24 & 1.32 & 1.41 & 1.45 & 1.49 \\
\hline
\end{tabular}

Jika $\mathrm{CR}<0,1$, maka nilai perbandingan berpasangan pada matriks kriteria yang diberikan konsistensi. Jika $\mathrm{CR}>0,1$ maka nilai perbandingan berpasangan pada matriks kriteria yang diberikan tidak konsistensi. Sehingga jika tidak konsistensi, maka pengisian nilai-nilai pada matriks berpasangan pada unsur kriteria maupun alternatif harus diulang.

13. Menyusun matriks baris antar alternatif versus krteria yang isinya hasil perhitungan proses langkah 7, langkah 8, dan langkah 9.

14. Hasil akhir berupa prioritas global sebagai nilai yang digunakan oleh pengambil keputusan berdasarkan nilai yang tertinggi.

\section{Analisa dan Pembahasan}




\section{Ariani Susanti}

doi.org/10.54209/jatilima. V3i2.152

Use case merupakan fungsionalitas dari suatu sistem, sehingga Admin sebagai pengguna sistem paham dan mengerti mengenai kegunaan sistem yang akan dibangun. Use case system pengambil keputusan dapat dilihat dalam gambar sebagai berikut:

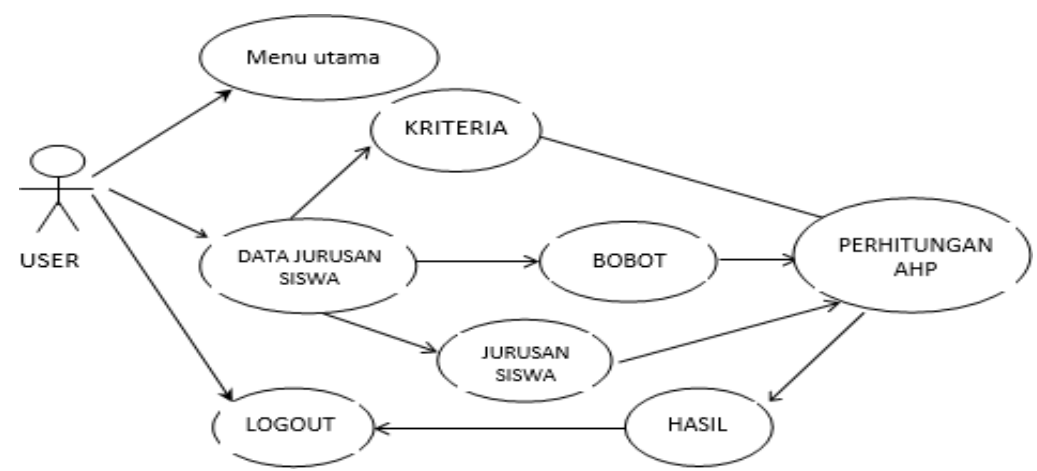

Gambar 1. Diagram Use Case

\section{Flowchart}

Sistem Flowchart menggambarkan aliran data yang diperlukan dalam sistem yang dibuat. Tujuan dari pembuatan system flowchart ini adalah menghasilkan laporan performansi untuk mengetahui keadaan saat ini sehingga dapat dilakukan perbaikan untuk masa yang akan datang.

\section{Implementasi}

Pengujian yang dilakukan adalah pengujian metode (method testing) dengan menggunakan metode AHP. Metode AHP sebuah kerangka untuk mengambil keputusan dengan efektif. Pengujian metode berfokus pada tindakan pengguna yang terlihat dan pengguna dapat mengenali output dari sistem, pengujian ini menjalankan sistem pada lingkungan yang aktif dengan menggunakan data yang benar. Berikut tampilan dari halaman index.php yang dapat dilihat pada Gambar 3.

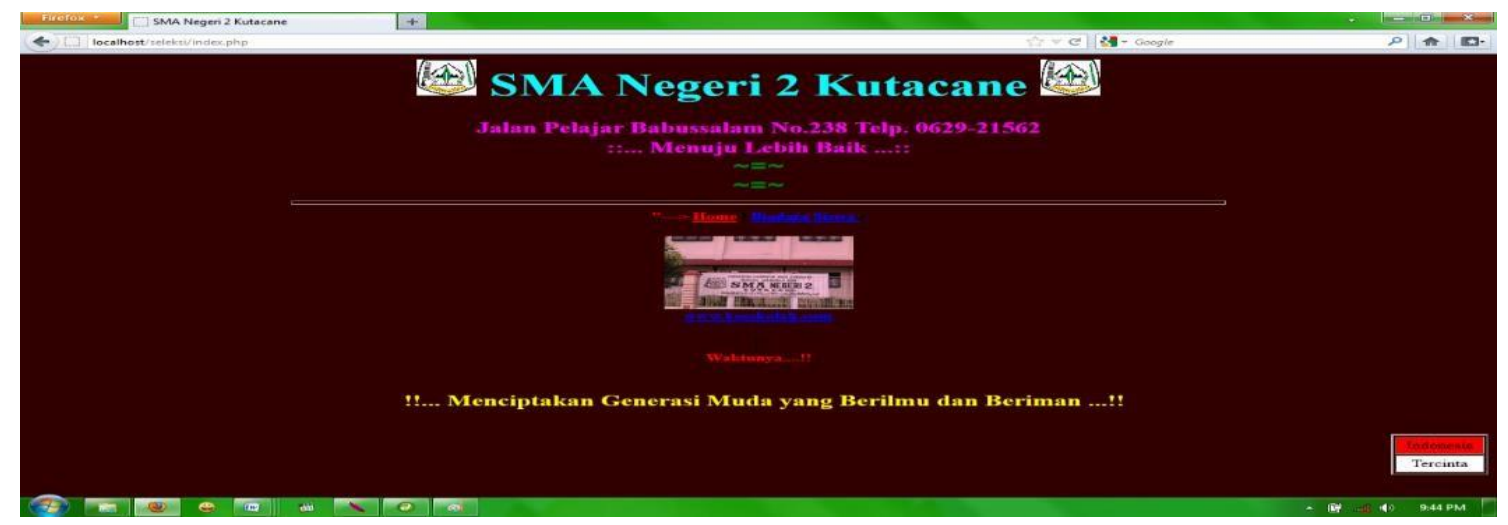

Gambar 2. Tampilan Form Utama

Pengolahan data siswa adalah proses menambah dan menghapus data seluruh siswa yang terdapat pada database. Halaman yang berfungsi untuk mengolah data siswa terdapat pada Gambar 3. 


\section{Ariani Susanti}

doi.org/10.54209/jatilima. V3i2.152

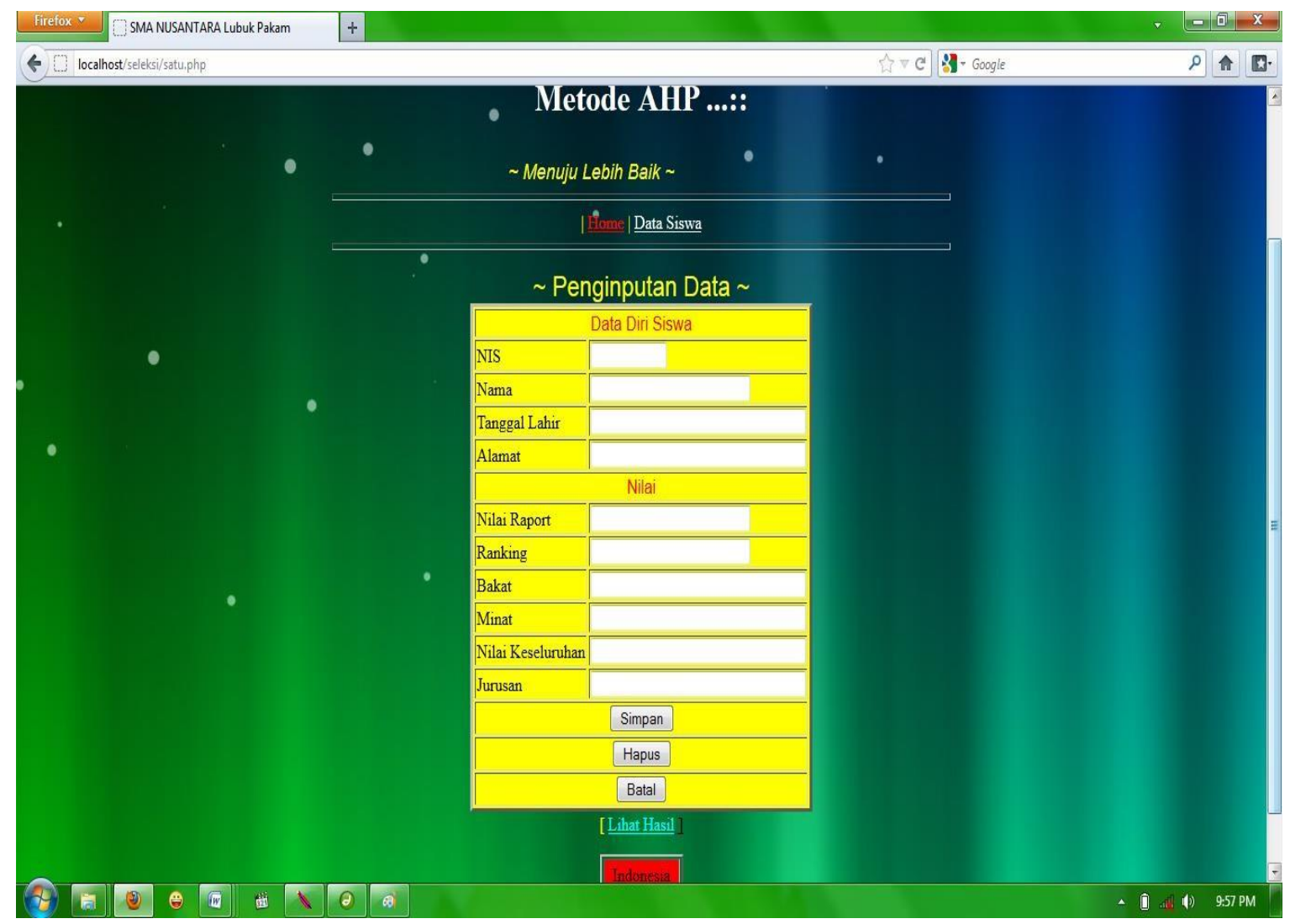

Gambar 3. Form Input Biodata Siswa

Sebagai hasil akhir dari aplikasi penentuan jurusan siswa tersebut dapat dilihat pada tampilan form output keseluruhan yang dapat dilihat pada Gambar 4.

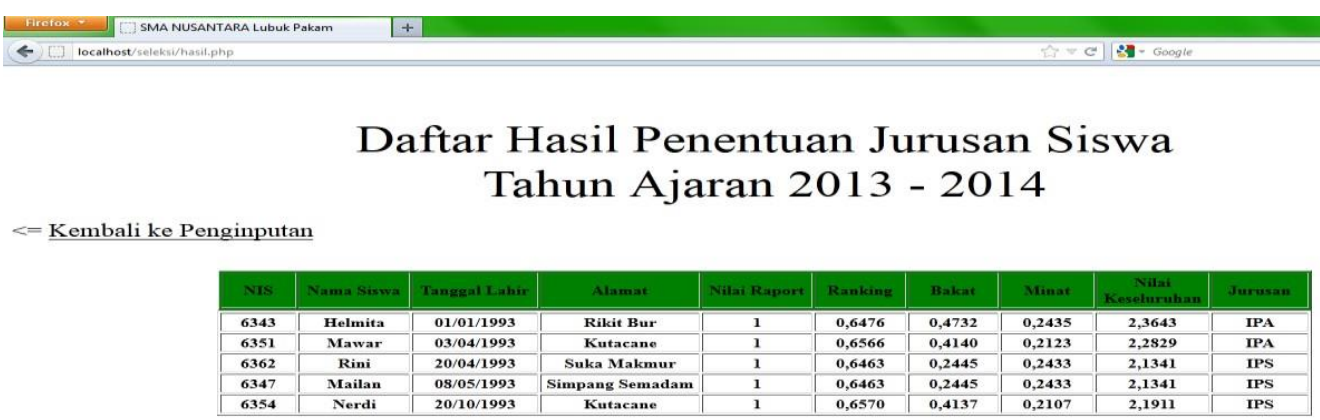

Gambar 4. Form Output Keseluruhan

\section{Kesimpulan}

Dengan adanya kesimpulan dan saran ini dapatlah diambil suatu perbandingan yang akhirnya dapat memberikan perbaikan- perbaikan pada masa yang akan datang. Adapun 


\section{Ariani Susanti}

doi.org/10.54209/jatilima. V3i2.152

kesimpulan yang penulis peroleh adalah sebagai berikut: Cara menentukan jurusan siswa pada SMA Negeri 2 Kutacane ditentukan dari Nilai raport, Ranking, Bakat, dan Minat Siswa. Dalam penentuan jurusan metode Analytic Hierarchy Process (AHP) bisa membantu dalam mengambil keputusan terhadap beberapa alternatif yang harus diambil dengan kriteria yang menjadi bahan pertimbangan. Dengan dirancang sistem aplikasi pengambilan keputusan penentuan jurusan siswa SMA Negeri 2 Kutacane, dapat memudahkan wali kelas dalam menyeleksi siswa untuk penentuan jurusan.

\section{Reference}

[1] D. Apriadi and R. Kuswandhie, "SISTEM PENDUKUKUNG KEPUTUSAN PENENTUAN JURUSAN PADA SMA BINA SATRIA," JUSIM (Jurnal Sist. Inf. Musirawas), vol. 5, no. 02, 2020.

[2] R. Kurniasari and A. Fatmawati, "PENERAPAN ALGORITMA C4.5 UNTUK PENJURUSAN SISWA SEKOLAH MENENGAH ATAS," Komputa J. Ilm. Komput. dan Inform., vol. 8, no. 1, 2019.

[3] S. Susanti, D. A. Irawati, and R. Rismanto, "SISTEM PENDUKUNG KEPUTUSAN PENJURUSAN PADA SISWA SMA,” J. Inform. Polinema, vol. 3, no. 4, 2017.

[4] T. Y. Akhirina, D. Yulistyanti, A. Rusmardiana, and U. Pauziah, "Pengujian Sistem Pendukung Keputusan Penjurusan SMA di Banten menggunakan Metode Black Box," J. RESTI (Rekayasa Sist. dan Teknol. Informasi), vol. 2, no. 3, 2018.

[5] M. Mughniy, R. C. Wihandika, and B. H. Prasetio, "Sistem Rekomendasi Psikotes untuk Penjurusan Siswa SMA menggunakan Metode Modified K-Nearest Neighbor," J. Pengemb. Teknol. Inf. dan Ilmu Komput., vol. 2, no. 1, 2018.

[6] I. Y. dkk. Arifiana, "PKM Pengembangan Aplikasi I-PASS Untuk Mengetahui Minat Siswa SMA Diponegoro Ploso Jombang (Berdasarkan Teori Minat Holland)," Community Serv. Consort., vol. 1, no. 1, 2020.

[7] A. R. Kadafi, "Perbandingan Algoritma Klasifikasi Untuk Penjurusan Siswa SMA," J. ELTIKOM, vol. 2, no. 2, 2018.

[8] A. S. Wicaksono, S. H. Fitriasih, and Kustanto, "Sistem Pendukung Keputusan Penjurusan Siswa Sma N 1 Kawedanan Dengan Metode Topsis," J. TIKomSiN, vol. 5, no. 2, 2017.

[9] Sriani and R. A. Putri, "Analisa Sistem Pendukung Keputusan Menggunakan Metode Topsis Untuk Sistem Penerimaan Pegawai Pada Sma Al Washliyah Tanjung Morawa," J. Ilmu Komput. dan Inform., vol. 02, no. April, 2018.

[10] F. I.-R. P. Computer, "Sistem Pendukung Keputusan Penerimaan Jurnalis Menerapkan MultiObjective Optimization On The Basis Of Ratio Analysis (MOORA)," JURIKOM (Jurnal Ris. Komputer), vol. 5, no. 1, 2018.

[11] S. W. Sari and B. Purba, "Sistem Pendukung Keputusan Pemilihan Ketua Danru Terbaik Menggunakan Metode ARAS," Semin. Nas. Teknol. Komput. Sains SAINTEKS 2019, 2019.

[12] Y. Zai, Mesran, and E. Buulolo, "Sistem Pendukung Keputusan untuk Menentukan Buah Rambutan Dengan Kualitas Terbaik Menggunakan Metode Weighted Product (WP)," Media Inform. Budidarma, vol. 1, no. 1, 2017.

[13] M. R. Noviansyah, W. Suharso, D. R. Chandranegara, M. S. Azmi, and M. Hermawan, "Sistem Pendukung Keputusan Pemilihan Laptop Pada E-Commerce Menggunakan Metode Weighted Product," Pros. SENTRA (Seminar Teknol. dan Rekayasa), vol. 0, no. 
5, 2019.

[14] Y. A. Saragih, J. T. Hardinata, and M. R. Lubis, "Sistem Pendukung Keputusan Pemilihan Sekolah SMA Swasta Terbaik Dengan Menggunakan Metode PROMETHEE Di Kota Pematangsiantar," BRAHMANA J. Penerapan Kecerdasan Buatan, vol. 1, no. $1,2019$.

[15] M. Arsyad, "Perancangan Sistem Pendukung Keputusan Pemilihan Kepala Sekolah Terbaik Tingkat Kabupaten Deli Serdang Menggunakan Metode Analytic Hierarchy Process (Ahp)," J. Inform. Pelita Nusant., vol. 4, no. 2, 2019.

[16] G. P. Sanyoto, R. I. Handayani, and E. Widanengsih, "Sistem Pendukung Keputusan Pemilihan Laptop Untuk Kebutuhan Operasional Dengan Metode AHP (Studi Kasus: Direktorat Pembinaan Kursus Dan Pelatihan Kemdikbud)," J. Pilar Nusa Mandiri, vol. 13, no. 2, 2017.

[17] R. K. Sitorus, "SISTEM PENDUKUNG KEPUTUSAN PEMILIHAN SEKOLAH TERBAIK DI KOTA MEDAN DENGAN MENGGUNAKAN METODE AHP (Studi Kasus : Dinas Pendidikan Kota Medan)," J. Ilm. INFOTEK, vol. 2, no. 1, 2017. 